\title{
Gestação e vivência da espiritualidade: letramento e autopercepção
}

\author{
Gestation and experience of spirituality: literacy and self-perception \\ Embarazo y experiencia de espiritualidad: alfabetización y autopercepción
}

\begin{abstract}
RESUMO
Objetivo: Investigar o letramento em saúde da gestante, assim como o significado atribuído ao período gestacional e autoconsciência. Métodos: Trata-se de um estudo exploratório descritivo com abordagem qualitativa, no qual foi realizada uma roda de conversa com gestantes já no segundo trimestre da gestação com participantes do projeto de extensão Bem Nascer, promovido pela faculdade. Essa roda de conversa foi realizada em uma unidade básica de saúde situada no bairro de Santa Rita, em Vila Velha - ES, onde foram entrevistadas 11 participantes. Resultados: Os resultados indicaram que ainda há uma fragilidade em relação ao letramento em saúde referente ao período gestacional e que a espiritualidade e a autorreflexão estão fortemente vinculadas a essa fase da vida feminina. Conclusão :Deve-se garantir que a mulher tenha um melhor conhecimento sobre 0 momento da gestação, para que se possa compreender cada passo, e que o seu acolhimento seja singular, considerando a sua espiritualidade, e oportunizando o empoderamento frente ao período gestacional, ao parto e ao puerpério.
\end{abstract}

DESCRITORES: Espiritualidade; Letramento; Autoconsciência; Gestação.

\section{ABSTRACT}

Objective: To investigate the health literacy of pregnant women, as well as the meaning attributed to the gestational period and self-awareness. Methods: This is a descriptive exploratory study with a qualitative approach, in which a conversation circle was held with pregnant women in the second trimester of pregnancy with participants in the Bem Nascer extension project, promoted by the college. This conversation was held at a basic health unit located about Santa Rita, in Vila Velha - ES, where 11 participants were interviewed. Results: The results indicated that there is still a weakness in relation to health literacy related to the gestational period and that spirituality and self-reflection are strongly linked to this phase of female life. Conclusion: It must be ensured that the woman has a better knowledge about the moment of pregnancy, so that each step can be understood, and that her welcoming is unique, considering her spirituality, and enabling empowerment in the face of the gestational period, while childbirth and the puerperium.

DESCRIPTORS: Spirituality; Literacy; Self-Awareness; Gestation.

\section{RESUMEN}

Objetivo: Investigar la alfabetización en salud de la gestante, así como el significado atribuido al período gestacional y la autoconciencia. Métodos: Se trata de un estudio exploratorio descriptivo con enfoque cualitativo, en el que se realizó un círculo de conversación con gestantes en el segundo trimestre de gestación con participantes en el proyecto de extensión Bem Nascer, promovido por la facultad. Esta conversación se realizó en una unidad básica de salud ubicada en el barrio de Santa Rita, en Vila Velha - ES, donde se entrevistó a 11 participantes. Resultados: Los resultados indicaron que aún existe una debilidad en relación a la alfabetización en salud relacionada con el período gestacional y que la espiritualidad y la autorreflexión están fuertemente ligadas a esta fase de la vida femenina. Conclusión: Se debe asegurar que la mujer conozca mejor el momento del embarazo, para que se entienda cada paso, y que su acogida sea única, considerando su espiritualidad, y posibilitando el empoderamiento de cara al período gestacional, mientras parto y puerperio.

DESCRIPTORES: Espiritualidad; Alfabetización; Autoconciencia; Embarazo.

RECEBIDO EM: 25/05/2020 APROVADO EM: 26/05/2020

\section{Thays Ferreira Nascimento}

Enfermeira.

ORCID: 0000-0002-6874-3228 


\author{
Hevellyn Andrade Faller Régino \\ Enfermeira. \\ ORCID: 0000-0003-3260-8523
}

\title{
Evandro Bernardino Mendes de Melo
}

Enfermeiro. Mestre em Enfermagem. Universidade Federal do Espírito Santo. ORCID: 0000-0002-1772-3083

\section{Livia Perasol Bedin}

Enfermeira.

ORCID: 0000-0001-8228-6468

\section{Priscilla Silva Machado}

Enfermeira. Doutora em Enfermagem. Mestre em Saúde Coletiva.

ORCID: 0000-0001-5134-2914

\section{Claudia Curbani Vieira Manola}

Enfermeira. Mestre em Administração.

ORCID: 0000-0002-0925-4432

\section{INTRODUÇÃO}

E studos reforçam que a espiritualidade é um considerável aspecto do significado da vida humana, e que no interior dos sentimentos encontramos sua real natureza ${ }^{(1)}$. De acordo com estudo $^{(2)}$, o profissional de saúde deve considerar a espiritualidade como essência do indivíduo, não descartando esse aspecto do seu cuidado.

O letramento em saúde, por sua vez, visa identificar o conhecimento e a capacidade que a pessoa tem em receber, processar e compreender as informações de saúde, e aplicar as mesmas em seu dia a dia, com intuito de melhorar a sua qualidade de vida. Conhecer o letramento em saúde do cliente ajuda o profissional de saúde atuar melhor de forma que venha favorecer a promoção, e prevenção de doenças ao paciente ${ }^{(3,4)}$.

Há uma fragilidade em relação ao conhecimento da gestante sobre as fases em que ela passa durante o período gestacional e até mesmo parto e puerpério. A gestação é uma fase em que a mulher passa por diversas transformações, sejam elas físicas, emocionais e psicológicas. Em se tratando da primeira gestação, esse momento se torna ainda mais intenso, pois a mulher enfrenta pela sua primeira experiência materna ${ }^{(5,6)}$.

O período gestacional, além de mudar a mulher fisicamente, é uma fase em que elas passam por transformações de valores espirituais e emocionais, e cada mulher responde a esse período de formas diferenciadas. Durante a gestação, a mulher é tomada por uma série de sentimentos, o que causa uma série de conflitos internos ${ }^{(7,8)}$.

Destaca-se a importância de o enfermeiro ter capacidade e habilidade em acolher suas clientes e familiares, para que haja uma boa relação entre eles. Além disso, é preciso saber mediar as informações de forma favorável ao seu entendimento, viabilizando qualidade de vida ${ }^{(3)}$.

Portanto, este trabalho visa investigar espiritualidade, letramento em saúde da gestante, assim como o significado atribuído ao período gestacional e à autoconsciência. Para isso, foi utilizada como metodologia a realização de encontros na Unidade Básica de Saúde do bairro de Santa Rida, em Vila Velha $E S$, a partir da aplicação de um questionário com três perguntas norteadoras. Como resultados e discussão, pôde-se observar a participação das gestantes durante toda a pesquisa, o que favoreceu a compreensão do questionário.

\section{METODOLOGIA}

Trata-se de um estudo exploratório, descritivo e com abordagem qualitativa, no qual foi realizada uma roda de con- versa com gestantes que estão no segundo trimestre da gestação, as quais são participantes do projeto de extensão Bem Nascer, promovido pela faculdade. Essa roda de conversa foi realizada em uma Unidade Básica de Saúde situada no bairro de Santa Rita, em Vila Velha - ES, onde foram entrevistadas 11 participantes do grupo da roda de conversa, com mulheres de idades entre 22 e 42 anos.

Foram realizados encontros em forma de bate-papo e roda de conversas com essas gestantes com temas relacionadas ao pré-natal, ao parto e ao puerpério, abrangendo, também, os primeiros cuidados com o recém-nascido, como a amamentação, o banho humanizado e a higiene com o coto umbilical. Também se explicou às participantes sobre seus direitos e deveres durante as consultas de pré-natal e parto.

Após a roda de conversa, apresentaram-se os objetivos da pesquisa e como funcionaria. Em sequência, foi aplicado o Termo de Consentimento Livre Esclarecido (TCLE), para que todas pudessem preenchê-lo e assiná-lo, assim, comprovando a sua concordância em participar da pesquisa.

Foi realizado um questionário contendo as informações sociodemográficas com as seguintes informações: sexo, idade, escolaridade, quantidade de gestações, e se a gestação atual havida sido planejada. Além disso, elencaram-se as seguintes pergun- 
tas norteadoras para a pesquisa: "Qual o seu entendimento em saúde gestacional?", "O que fazer para ter saúde gestacional?", "Qual o sentido do período gestacional em relação à vida?" e "Você discute com você mesma a sua gestação e parto? Como?”, em busca de identificar o letramento em saúde dessas parturientes, a espiritualidade e a autoconsciência.

Para construção dos resultados, foi adotado o método de análise proposto por Bardin, seguindo suas três fases: pré-análise, exploração do material e o tratamento dos resultados.

Este projeto de pesquisa foi submetido ao Comitê de Ética e Pesquisa com Seres Humanos do Centro Universitário Católico do Espírito Santo em consonância aos aspectos éticos da pesquisa envolvendo seres humanos, de acordo com o preconizado pela Resolução n. ${ }^{\circ}$ 466/2012, do Conselho Nacional de Saúde (CNS), sendo aprovado sob número do Parecer 3.707.456.

\section{RESULTADOS E DISCUSSÃO}

Foram entrevistadas 11 gestantes do total de 15 cadastradas no segundo semestre, com idades entre 22 e 42 anos, e as entrevistas foram realizadas em uma Unidade Básica de Saúde da região de Vila Velha - ES, onde as entrevistadas são gestantes participantes da roda de conversa promovida pelo Projeto de Extensão Bem Nascer.

A Tabela 1 organiza os dados sociodemográficos das gestantes, as quais são identificadas como nome de flor.

De acordo com os dados demonstrados na Tabela 1, pode-se perceber que as gestantes possuem idades e escolaridades distintas e que algumas planejaram a gestação, e outras não. Porém, mesmo com esses dados divergentes, todas possuem um mesmo grau de entendimento em relação à saúde gestacional, e passam por situações de autoconsciência semelhantes. A seguir serão discutidas respostas das perguntas norteadoras e, para melhor visualização e entendimento, os relatos das gestantes foram organizados em quadros.

Nos Quadros 1 e 2, demonstra-se o letramento em saúde da gestante, e, de acordo com os relatos, podemos compreender as percepções quanto à saúde na gestação, e o que elas fazem para manter a saúde gestacional. Para a identificação do letramento da gestante em relação ao período gestacional, foi realizada uma entrevista individual em forma de questionário, constituído por duas perguntas norteadoras, sendo elas: "Qual o seu entendimento em saúde gestacional?" e "Como você faz para ter saúde na gestação?”. Com isso, podemos observar que, para essas gestantes, a saúde gestacional está vinculada à saúde tanto da gestante $\mathrm{e}$ quanto do bebê, e que sua saúde influencia na saúde do feto, como se pode verificar no Quadro 1:

\section{Tabela 1. Dados sociodemográficos das gestantes. Vila Velha, ES, Brasil, 2018}

\begin{tabular}{|c|c|c|c|c|c|}
\hline Identificação & Idade & Estado civil & Escolaridade & Quantidade de Gestação & Gestação planejada? \\
\hline Lírio & 32 a 42 anos & Casada & Ensino médio completo & Maior de 6 & Sim \\
\hline Rosa & 32 a 42 anos & Casada & Ensino médio completo & Menor de 4 & $\operatorname{Sim}$ \\
\hline Tulipa & Menor de 22 anos & Casada & $\begin{array}{l}\text { Ensino Fundamental } \\
\text { incompleto }\end{array}$ & Menor de 4 & Não \\
\hline Lilac & 22 a 32 anos & Solteira & $\begin{array}{l}\text { Ensino fundamental } \\
\text { incompleto }\end{array}$ & 4 a menos de 6 & Não \\
\hline Margarida & 22 a 32 anos & Casada & Ensino médio completo & Menor de 2 & $\operatorname{Sim}$ \\
\hline Palma & 22 a 32 anos & Solteira & Ensino médio completo & Menor de 4 & Não \\
\hline Tango & 32 a 42 anos & Casada & Ensino médio completo & Menor de 2 & Sim \\
\hline Girassol & 32 a 42 anos & Casada & Ensino médio incompleto & 4 a menos de 6 & Não \\
\hline Iris & 22 a 32 anos & Solteira & Ensino médio completo & Menor de 2 & Não \\
\hline Cerejeira & Menor de 18 anos & Solteira & $\begin{array}{l}\text { Ensino fundamental } \\
\text { completo }\end{array}$ & Menor de 2 & Não \\
\hline Liatris & Menor de 22 anos & Solteira & $\begin{array}{l}\text { Ensino fundamental } \\
\text { incompleto }\end{array}$ & Menor de 4 & Não \\
\hline
\end{tabular}

\section{Quadro 1. Entendimento das gestantes sobre saúde gestacional. Vila Velha, ES, Brasil, 2018}

\section{QUAL O SEU ENTENDIMENTO EM SAÚDE GESTACIONAL? COMO VOCÊ FAZ PARA TER SAÚDE NA GESTAÇÃO?}

Flor Tulipa - "Saúde gestacional é a saúde da grávida e do bebê, e, para manter a minha saúde na gestação, eu faço uma alimentação saudável, realizo atividade física, e não ingiro bebidas alcoólicas e ainda faço uso de ácido fólico e ferro"

Flor Iris - "Saúde gestacional é quando o bebê e a mãe estão bem, e para uma melhor gravidez procuro me alimentar bem e nas horas certas" 


\section{artigo}

Flor Liatris - "Entendo que para o bebê está bem, eu preciso estar, para isso eu tento me alimentar de forma saudável e evitar muito sal, comidas enlatadas, embutidos, refrigerante. Não consumo bebidas alcoólicas, nem fumo e não faço uso drogas. Pratico exercícios pelo menos 2 ou 3 vezes na semana"

Flor Rosa - "Muito importante para a saúde do bebê é eu me alimentar corretamente, para não ter complicação na gestação"

Flor Girassol - "O entendimento que eu tenho é que a minha saúde é a saúde do bebê porque ele depende de mim. Eu como bastante verdura, fruta, e procuro sempre dançar como exercício físico e tomo os remédios passados pela doutora."

Flor Margarida - "Eu não busco fazer nada, até foi recomendado fazer exercício, mas eu não consigo, e não consigo fazer dieta"

\section{Quadro 2. Entendimento das gestantes sobre saúde gestacional. Vila Velha, ES, Brasil, 2018}

\section{QUAL O SEU ENTENDIMENTO EM SAÚDE GESTACIONAL? COMO VOCÊ FAZ PARA TER SAÚDE NA GESTAÇÃO?}

Flor Lilac - "Fazer o pré natal, e ir às consultas e ingerir muita água como recomendado, me alimentar bem, não beber, não fumar"

Flor Palma - "Para saúde gestacional é primordial realizar o pré natal, ir às consultas sem faltar"

\section{Quadro 3. Depoimento sobre o período gestacional. Vila Velha, ES, Brasil, 2018}

\section{QUAL O SENTIDO DO PERÍODO GESTACIONAL EM RELAÇÃO À VIDA?}

Flor Lírio - "para mim é um milagre, sinto como se hoje o sentido da minha vida e dos meus propósitos são fortalecidos pelo meu bebê"

Flor Rosa - "é um amor inexplicável, uma sensação de plenitude e crença no futuro"

Flor Girassol - "é um momento único e muito bonito, de certeza no melhor."

Flor Tulipa - "está sendo bom e ruim ao mesmo tempo, muitas incertezas e preocupações"

Flor Iris - "em relação à vida tudo muda, nos tornamos melhores"

Flor Cerejeira - "Depois que engravidei amadureci muito, sou mais objetiva, tolerante compreensiva"

Flor Tango - "pra mim e meu marido é uma realização"

Durante a entrevista também podemos identificar que, para elas, a saúde gestacional está relacionada com a realização das consultas de pré-natal, tendo em vista que, através do pré-natal, elas possuem orientações e recomendações, o que favorece a promoção da saúde e influencia na saúde de seu filho, conforme observado no Quadro 2:

As gestantes entrevistadas afirmam se prepararem para o parto, e, com isso, buscam seguirem orientações feitas pelos profissionais de saúde. Outras seguem experiências passadas de família para família. As mulheres criam expectativas quanto ao parto, devido ao conhecimento que possuem sobre o assunto ${ }^{(9)}$.

Essa entrevista buscou compreender o entendimento que as gestantes possuem em relação à saúde gestacional, e o que elas fazem para manter essa saúde. Destaca-se a importância do método de identificação de letramento em saúde dos usuários pelo o enfermeiro, para que, assim, seja ofertado um melhor cuidado e educação em saúde ${ }^{(4)}$.

Em relação à saúde gestacional, as ges- tantes compreendem que está relacionada com saúde dela e do bebê e que, para manter um melhor desenvolvimento, elas realizam dietas e praticam exercícios recomendados pelos profissionais de saúde. Porém, outras relatam não conseguirem colocar em prática essas orientações. Para tanto, estudo ${ }^{(10)}$ relata que o profissional deve acolher a gestante respeitosamente, favorecendo uma relação entre os mesmos e ofertar os cuidados de forma singular.

Além disso, algumas gestantes entrevistadas ressaltam que, para elas manterem a saúde, vão às consultas de pré-natal. A assistência ao pré-natal facilita a descoberta e o tratamento eficaz de doenças que podem prejudicar na gestação, e identificar fatores de risco para saúde mãe-bebê(11).

Deve haver um acompanhamento continuado pela equipe de saúde em relação ao desenvolvimento da mãe e do bebê através das consultas durante a gestação. A assistência ao pré-natal é a realização de diversos procedimentos, tanto educativos quanto clínicos, com intuito de propor- cionar um melhor acompanhamento da evolução da gestação desde o início até o período pós-parto, promovendo saúde à mãe e ao bebê $\hat{e}^{(9,12)}$.

Para que seja garantida uma melhor saúde gestacional, é importante que a gestante participe das consultas de pré-natal e que realize as orientações feitas durante a consulta pelo profissional de saúde. Além disso, o acompanhamento deve ser de forma humanizada ${ }^{(12)}$.

Portanto, em relação ao letramento em saúde, ressalta-se a importância da identificação do grau de compreensão da população, pois, através de pesquisas, ainda se observa que as pessoas possuem um grau de entendimento, mas nem sempre o suficiente para aplicar essas orientações em saúde à vida ${ }^{(3)}$.

Para a identificação da espiritualidade da gestante, foi pesquisado o sentido do período gestacional em relação à vida para as mulheres entrevistadas no projeto Bem Nascer, os quais esses relatos e depoimentos serão demonstrados a seguir no Quadro 3: 
Através desses depoimentos relatados por essas gestantes, pudemos observar uma mistura de sentimentos em relação à gestação. Além de muitas relatarem durante a roda de conversa que esse momento tem sido de grandes transformações, tanto externo quanto interno, e que essa vivência tem despertado nelas amadurecimento enquanto pessoa.

O período gestacional, além de mudar a mulher fisicamente, é uma fase em que elas passam por transformações de valores espirituais e sentimentais, e cada mulher responde a esse período de formas diferenciadas ${ }^{(7)}$.

De acordo com as respostas dessas parturientes, compreendemos que a gestação tem trazido novos sentidos à vida dessas mulheres, considerando que todas relatam sobre crescimento pessoal, sendo visível a espiritualidade, diante desse momento, não só na vida da parturiente, mas também na vida de seus familiares.

Autores $^{(13)}$ compreendem o parto como um divisor de águas para a mulher, no qual elas constroem e reconstroem seus sentimentos a partir de relatos e vivências do dia a dia. Para outros autores ${ }^{(14)}$, durante o período gravídico a mulher passa por um desenvolvimento, no qual ela necessita de um acompanhamento constante por profissionais de saúde, tendo em vista que devem promover uma comunicação com ela, favo- recendo com que vivencie esse momento de forma positiva.

A busca do sentido que algo, ou algum momento traz à vida, está associada à espiritualidade, de modo que, é singular a cada um, e é o que traz sentido à vida, ao ser humano, estando ou não relacionado com alguma crença. Ainda ressalta-se a importância de que o enfermeiro identifique a espiritualidade do cliente, pois, assim, pode ofertar um melhor cuidado, além disso, de forma humanizada ${ }^{(15)}$.

Em relação ao período gestacional, autores ${ }^{(16)}$ descrevem como um momento muito especial para a mulher, pois ela estará gerando uma nova vida, um novo ser. Nessa direção, autores ${ }^{(17)}$ ressaltam sobre a espiritualidade, a qual deve ser sempre levada em conta pelo profissional de saúde, bem como o sentido da vida, garantindo que o cliente vivencie esse momento de forma positiva.

Para as gestantes entrevistadas, a gestação é um momento inexplicável. Algumas relatam que se trata de uma realização tanto para ela quanto para o marido, o que nos leva à necessidade de compreender esse evento. A a espiritualidade deve estar presente no âmbito da saúde, em busca de que o profissional e o paciente possam vivenciar esse processo da melhor forma possível, levando em consideração não somente o sentimento do paciente, mas sim de toda a sua família que está vivenciando este momento ${ }^{(18)}$.

Além do letramento e da espiritualidade da gestante, este trabalho visa identificar a autoconsciência das gestantes entrevistadas, com intuito investigar se faziam a autorreflexão desse período de gestação e do parto na vida delas. Para tanto, foi utilizado um questionário em que havia como perguntas norteadoras: "Você discute com você mesmo a sua gestação e parto? Como?" conforme demonstrado no Quadro 4, juntamente com as respostas:

Observa-se, de acordo com as respostas, que as gestantes entrevistadas discutem consigo mesmas sobre o momento da gestação, de modo que relatam medo e ansiedade como os maiores precursores desse processo. Ressalta-se que a gestação como um evento na vida da mulher que gera medo e ansiedade, o que cabe ao profissional de enfermagem, durante a consulta de pré-natal, ofertar um cuidado de forma integral e individual, para que venha favorecer na minimização destes, além de contribuir numa melhor relação entre o profissional e a gestante ${ }^{(19)}$.

Durante a entrevista, algumas dessas gestantes expuseram dúvidas sobre o momento da gravidez, pois nem todas estão em uma gestação planejada. Outras relatam que esse momento nem deveria estar acontecendo, o que gera uma prevalência cada vez maior do medo em

\section{Quadro 4. Depoimento das gestantes sobre a autorreflexão gestacional. Vila Velha, ES, Brasil, 2018}

\section{VOCÊ DISCUTE COM VOCÊ MESMA A SUA GESTAÇÃO E PARTO? COMO?}

Flor Tulipa - "sim, por ser a segunda gestação já estou à espera do momento, e muito ansiosa e com medo. Pergunto-me se vou conseguir e aguentar"

Flor Cerejeira - "eu só penso que não poderia acontecer, mas estou feliz, porém tenho um pouco de medo do parto, fico muito confusa sobre tudo que me aconteceu"

Flor Girassol - "penso comigo mesma sobre minha gestação e meu parto, penso como deveria ser, queria muito o parto normal, mas devida a minha gestação ser de risco por conta da diabete gestacional e minha idade avançada, acho que não será possível. E tenho medo porque já tive duas cesáreas e essa será a terceira"

Flor Margarida - "discuto comigo mesma, eu ainda tenho muita dúvida do parto que quero ter, pois quero muito o parto normal, mas tenho medo de ficar sofrendo por muito tempo e não ter passagem e não der certo no final, não queria cesárea mas vejo que vai ser o melhor pra mim pois posso agendar e não terá nenhuma intercorrência, discuto comigo mesmo o que vai ser melhor e não para a minha filha".

Flor Liatris- "Sim, eu me questiono sobre a minha gestação, no início não quis, mas hoje me sinto melhor, com o passar do tempo e aceitação tenho mais momentos de reflexão" 
relação ao parto, e do que ainda está por vir. A gestante durante o período gestacional passa por alterações psicológicas, já que essa nova fase provoca um impacto em sua vida pessoal e familiar. Ressalta-se que esse período faz que a mulher fique cada vez mais ansiosa e, consequentemente, vulnerável a perturbações emocionais ${ }^{(20)}$.

Em relação ao planejamento da gestação pesquisadores ${ }^{(8)}$, através de estudos realizados, puderam observar que é comum que as mulheres possuam um desejo inconsciente de ter o bebê .Porém, conscientemente não se planejam para esse processo gestacional, o que gera conflitos entre si, ocasionando medo, ansiedade, aceitação ou rejeição da situação.

Algumas gestantes entrevistadas relatam um grande desejo de ter o parto normal. Umas se sentem inseguras, outras se acham insuficientes para ter o parto por via vaginal, levando a acreditar que a cesárea seja a melhor opção. Apesar das mulheres terem maiores preferências no parto vaginal, o alto índice de cesárea no país ainda prevalece, fazendo com que a gestante seja influenciada durante a gestação, por meio, inclusive da escassez de informação durante o pré-natal ${ }^{(21)}$.

Durante o pré-natal, a gestante deve ser informada sobre cada parto, e suas indicações e contraindicações, o processo fisiológico do período gravídico, assim como esclarecimento de mitos e os seus direitos durante o parto de acordo com as diretrizes. Assim, é possível que se tenha uma experiência positiva, e um menor risco de complicação posterior ${ }^{(9)}$.

Autores $^{(21)}$ puderam observar que as mulheres possuem suas preferências quanto ao parto, tendo em vista que umas preferem a via de parto vaginal devido à recuperação pós-parto ser mais rápida. Outras, por sua vez, preferem a cesárea, por medo da dor que o parto vaginal traz. Com isso, eles reforçam que o pré-natal possui um papel fundamental quanto às informações educativas, devido às orientações quanto ao parto, assim, ajudando as gestantes na melhor decisão diante a sua escolha, com intuito de minimizar intercorrências des-

\section{O Ministério da}

Saúde preconiza,

no mínimo, seis

consultas de pré-

natal, o que é

recomendado desde

o início da gestação,

para que seja feito o

acompanhamento

da gestante e $o$

desenvolvimento

do seu feto, além

das orientações

oferecidas pelo

profissional de saúde. necessárias, além de contribuir para o empoderamento da mulher.

\section{CONSIDERAÇÕES FINAIS}

A gestação é uma fase na vida da mulher que acarreta diversas mudanças, sejam elas físicas emocionais e até mesmo sociais. De acordo com os relatos das gestantes durante as rodas de conversa e no preenchimento das respostas no questionário, pudemos compreender que o entendimento que elas têm em relação à saúde gestacional ainda é fragilizado, já que ressaltam entenderem como saúde gestacional a condição delas e o bebê estarem bem, o que torna o seu conhecimento raso, e a necessidade de uma melhor orientação ofertada pelo profissional de saúde em relação ao assunto, pois a saúde gestacional vai muito além do binômio mãe-bebê estarem bem.

O Ministério da Saúde preconiza, no mínimo, seis consultas de pré-natal, o que é recomendado desde o início da gestação, para que seja feito o acompanhamento da gestante e o desenvolvimento do seu feto, além das orientações oferecidas pelo profissional de saúde.

É importante, então, a comunicação entre o profissional de saúde e a gestante, pois, assim, elas passam a compreender os seus direitos, como a escolha do acompanhante e saber claramente sobre como ocorre cada tipo de parto e seus benefícios, descritos na rede cegonha, e isso torna mais fácil que elas entendam a importância de priorizar o parto vaginal e minimizar as violências relacionadas à obstetrícia, pois, quanto mais restrito o conceito de saúde relacionado ao letramento, menores condições a gestante terá em fazer escolhas pertinentes durante a gestação, além de minimizar seus medos e ansiedade.

O sentido da vida deve ser considerado pelo profissional de saúde no atendimento, não somente os sinais e sintomas, mas sim a espiritualidade do cliente. Em relação à gestante, deve-se compreender que ela passa por diversas modificações no que se considera uma transação da vida, que é o ato de ser mãe. Para isso, é importante que 
o seu acolhimento seja realizado de forma humanizada, garantindo a ela a liberdade de expressar sua fé e vivenciar o momento de uma maneira única.

A espiritualidade deve ser relacionada à saúde e ao cuidado, o qual deve ser ofertado de forma holística, assim, garantindo uma segurança não só à mulher, mas a toda a sua família, que está passando por uma nova fase da sua vida, juntamente com ela.

Esse momento é muito importante na vida da gestante, e a autorreflexão segundo os estudos, faz com que a gestante se fortaleça. Portanto, cabe ao enfermeiro, como profissional de saúde, incentivar que haja essa autoconsciência da gestante em relação à sua gestação, garantindo o empoderamento necessário. É preciso saber que o parto é dela e que será realizado da maneira em que ela se sentir melhor e mais confortável.

De acordo com os estudos realizados, entendemos que deve-se garantir que a mulher tenha um melhor conhecimento sobre o momento da gestação, para que possa compreender cada passo e vivenciar o momento de forma única, e que o seu acolhimento seja singular, levando em conta a sua espiritualidade, e oportunizando o empoderamento frente ao período gestacional, parto e puerpério.
É importante destacar o fato de que novas pesquisas devem ser realizadas no campo da saúde gestacional, de modo que novas questóes sejam respondidas e compreendidas por toda sociedade a partir de olhares científicos. Desse modo, esta pesquisa não encerra as discussões sobre o período de gestação, e sim, dá continuidade e mantém abertas as portas aos projetos e pesquisas que têm sido desenvolvidos sobre o tema, estando cientes de inúmeras outras abordagens possíveis que, por limitação temporal e espacial, não tenham sido aqui contempladas.

\section{REFERÊNCIAS}

1. Reginato V, et al. Espiritualidade e saúde: uma experiência na graduação em medicina e enfermagem. Trab. Educ. Saúde. 2016;14(1):237-255.

2. Leão EMFS. Novas Perspectivas entre resiliência e espiritualidade através de escalas psicológicas. Tese (Pós Graduação em Psicologia Social) - Universidade de São Paulo. São Paulo, 2017. $136 \mathrm{p}$.

3. Marques SRL, et al. Instrumentos de avaliação do letramento em saúde: revisão de literatura. Audiology - communication Resarch. 2017;22:1-12.

4. Araújo LSLR. O conceito de letramentonas pesquisas de práticas em enfermagem. C\&D - Revista Eletrônica da FAINOR. 2018;11(3):530-540.

5. Aching C, et at. Mães de primeira viagem: narrativas de muIheres em situação de vulnerabilidade no Brasil. Psicologia em estudo. 2016;21(2): 235-244.

6. Faria J, Martins GF. Empoderamento da mulher em projetos de assistência a gestação. Revista brasileira de ciências da vida. 2018;1-6.

7. Rodrigues CC. Maternidade e Espiritualidade: aspectos simbólicos. Revista Eletrônica em Ciências da Religião. 2015;6(13):467494.

8. Simas FB, et al. Significados da gravidez e da maternidade: discursos de primíparas e multíparas. Psicologia: Teoria e Prática. 2013;15(1):19-34.

9. Silva SPC, et al. Parto normal ou cesariana? Fatores que influenciam na escolha da gestante. Revista da Enfermagem da UFSM. 2014;4(1): 1-9.

10. Silva ALS, et al. Práticas de enfermeiras para promoção da dignificação, participação e autonomia de mulheres no parto normal. RESEARCH. 2015; 19(3):424-431.

11. Martins QPM, et al. Conhecimento de gestante no pré natal: Evidências para o cuidado de enfermagem. SANARE, Revista das políticas públicas. 2015; 14(2):65-71.

12. Ministério da Saúde (BR). Secretaria de atenção à saúde. Atenção ao pré-natal de baixo risco [Internet]. Brasília (DF): MS; 2012 [acesso em 11 out 2019]. Disponivel em: http://bvsms. saude.gov.br/bvs/publicacoes/cadernos_atencao_basica_32 prenatal.pdf

13. Matos $\mathrm{G}$, et al. A trajetória histórica das políticas de atenção ao parto no Brasil: uma revisão integrativa. Revista de enfermagem UFPE online. 2013; 7(esp):870-878.

14. Guedes CDFS, et al. Percepções de gestantes sobre a promoção do parto normal no pré natal. Revista Ciência Plural. 2017;3(2):87-98.

15. Caldeira $S$, et al. espiritualidade nos cuidados de enfermagem: revisão da divulgação científica em Portugal. Rev. Enf. Ref. 2011; 5(2):145-152.

16. Henriques C, et al. Adaptação da escala de avaliação da espiritualidade em mulheres grávidas. Revista Portuguesa de enfermagem na saúde mental. 2019; 21:9-15.

17. Thiengo PCS, et al. Espiritualidade e religiosidade no cuidado em saúde: Revisão integrativa. Cogitare Enfermagem. 2019;24(58692):1-12.

18. Lima R. Conversação sobre a morte no processo de cuidar: uma contribuição para a formação do enfermeiro. Tese (Programa de pós graduação em enfermagem) - Escola de enfermagem Anna Nery - UFRJ. Rio de Janeiro, 2017. 156 p.

19. Rodrigues IR, et al. Elementos constituintes da consulta de enfermagem no pré-natal na ótica de gestantes. Revista Rene. 2016;17(6):774-781.

20. Coutinho EC et al. Gravidez e parto: 0 que muda no estilo de vida das mulheres que se tornam mães? Revista Escola de Enfermagem USP. 2014;448(2):17-24.

21. Kottwitz $F$, et. al. Via de parto preferido por puérperas e suas motivações. Repositório digital. 2018;22(01):1-8. 